Théologiques

Théologiques

\title{
Choisir l'absence de repas : le jeûne
}

Implications théologiques d'une pratique dans le judaiisme, le christianisme et l'islam

\section{Florence Ollivry-Dumairieh}

Volume 23, numéro 1, 2015

Derniers repas

URI : https://id.erudit.org/iderudit/1040868ar

DOI : https://doi.org/10.7202/1040868ar

Aller au sommaire du numéro

\section{Éditeur(s)}

Faculté de théologie et de sciences des religions, Université de Montréal

ISSN

1188-7109 (imprimé)

1492-1413 (numérique)

Découvrir la revue

\section{Citer cet article}

Ollivry-Dumairieh, F. (2015). Choisir l'absence de repas : le jeûne : implications théologiques d'une pratique dans le judaïsme, le christianisme et l'islam.

Théologiques, 23(1), 107-137. https://doi.org/10.7202/1040868ar

\section{Résumé de l'article}

Tandis que le repas occupe une place importante dans la vie religieuse juive, chrétienne ou musulmane, il appert que la pratique du jeûne y occupe elle aussi une place centrale. Qu'implique cette prescription au plan théologique? Comprend-elle une exhortation à renoncer à nourrir l'organisme, à mépriser ce monde ? Ou bien a-t-elle au contraire pour fonction de nous préparer à célébrer les fruits de la Création au cours d'un repas? De nous permettre de mieux apprécier la saveur d'un " dé-jeûner " ? J'explore dans cet article les implications théologiques du jeûne dans le judaïsme, le christianisme et l'islam. J'étudie les écrits de certaines figures spirituelles (mystiques, moines, ascètes) relatifs à cette pratique et je m'efforce de comprendre quelle relation au corps, à la Création, à la vie et à la mort induit le jeûne dans les trois religions étudiées. 


\title{
Choisir l'absence de repas: le jeûne Implications théologiques d'une pratique dans le judaïsme, le christianisme et l'islam
}

\author{
Florence OlLivry-DumairieH* \\ Sciences des religions \\ Université de Montréal/ \\ École Pratique des Hautes Études (Paris)
}

«Pour que la sagesse divine, qui s'est fait entendre intelligiblement dans le cœur, fasse d'un homme son interprète, prenne en lui sa demeure, et puisse être exprimée sans déformation par sa langue, il faut que cet homme jê̂ne, veille et prie.»

(Massignon 1922, 501)

\section{Introduction $^{1}$}

C'est nourri par le placenta de sa mère que le fœtus peut grandir et se développer: point de vie sans nourriture. Lorsque le nouveau-né vient au monde, dès que le cordon est coupé, c'est par l'orifice de la bouche qu'il devra nécessairement s'alimenter pour se maintenir en vie: le désir de vivre

* Florence Ollivry-Dumairieh est doctorante en sciences des religions (Université de Montréal / Ecole Pratique des Hautes Études) et consacre sa thèse à l'œuvre de Louis Massignon (1883-1962). Ses champs de recherche sont: la mystique musulmane, le dialogue interreligieux et l'anthropologie religieuse du Proche-Orient. En 2006, elle a publié une étude historique consacrée à la gastronomie alépine: Les secrets d'Alep, une grande ville arabe révélée à travers sa cuisine (Actes Sud, Sindbad), et en 2011, un ouvrage consacré à l'histoire de la sériciculture et des échanges textiles et culturels en Méditerranée ( $L a$ soie et L'Orient, Éd. du Rouergue).

1. Nous souhaitons dire notre reconnaissance au Pr. Olivier Bauer qui nous a offert de contribuer à ce volume consacré aux «Derniers Repas » et exprimer notre gratitude au Frère Ignazio De Francesco, au Père Maurice Borrmans, à M. Antoine Paris, au Rabbin Leigh Lerner, à Dr. Sonia Sarah Lipsyc ainsi qu'à Mme Lydwine Olivier pour leur aide précieuse au cours de la rédaction de cet article. 
et le désir de se nourrir participent d'un même élan. Inversement, lorsqu'un être avance en âge et parvient au terme de sa vie, s'il perd l'appétit et cesse de vouloir se nourrir, on dira qu'il a perdu «le goût de vivre »: l'absence d'appétit de nourriture semble alors se confondre avec l'absence d'appétit pour la vie. L'expression «Dernier repas » annonce implicitement la proximité du trépas: car l'absence prolongée de nourriture conduit nécessairement au décès. Mourir d'inanition, c'est, comme l'indique l'étymologie latine «inanitio », mourir d'avoir prolongé un «état de vide », être demeuré trop longtemps le «ventre creux » : c'est être resté «à jeun » jusqu'à ce que mort s'ensuive. En l'absence de nourriture, le corps se décharne, s'amenuise, et bientôt, le souffle de vie quitte le corps de l'être qui a cessé de se nourrir. Il est nécessaire de se nourrir pour vivre. Sur le plan physiologique, la nourriture apparaît comme associée à la vie. Son absence à la mort.

Pourtant, nous constatons que la prescription du jeûne occupe une place centrale dans plusieurs religions : l'importance du Yom Kippour dans la religion juive, celle du carême pré-pascal dans la religion chrétienne, ou encore celle du jeûne du mois de Ramaḍân dans la religion musulmane, en témoignent. De plus, parmi les figures hagiographiques juives, chrétiennes ou musulmanes, on recense bien plus d'ascètes ayant observé des jeûnes exemplaires que de "bons vivants». Comme l'observe Olivier Assouly, dans l'idéal ascétique, "les nourritures sont des signes de désordre, de servitude, de matérialité et la marque d'une condition mortelle», si bien que «l'ascète semble résolu à mourir d'inanition» (Assouly 2002, 192).

Quelles sont les implications théologiques de la pratique du jeûne? Comprend-elle une exhortation à renoncer à nourrir ce corps, ou à mépriser ce monde ou cette vie? Les prescriptions religieuses relatives au jeûne sous-entendent-elles une forme de culpabilité à l'égard de toute manducation? Ou bien cette pratique a-t-elle, au contraire, pour fonction de nous préparer à célébrer les fruits de la Création au cours d'un repas? de mieux nous permettre d'apprécier la saveur d'un «dé-jeûner»? de purifier le corps du croyant avant un repas solennel, sacré? de nous permettre de retrouver une juste relation à la nourriture, au corps, au monde? Quelles sont les implications théologiques du jeûne?

Bien que le jeûne soit prescrit dans de nombreuses religions et traditions spirituelles, nous limiterons le cadre de notre étude à ce que l'historien comparatiste Michel Dousse appelle le «monothéisme abrahamique diversifié en ses trois expressions majeures »: c'est-à-dire le judaïsme, le christianisme et l'islam (Dousse 2002, 7). En effet, bien qu'elles ne conçoivent pas la figure d'Abraham de manière identique (Brague 2009, 
26-33), ce triptyque présente une certaine unité: car ces religions « unanimement confessent un même Dieu Un et Unique, Créateur de toutes choses, visibles et invisibles, et qui a parlé par les prophètes» (Dousse 2002, 23). Ainsi, nous tenterons d'analyser les implications théologiques de la prescription du jeûne dans le judaïsme, puis dans le christianisme et enfin dans l'islam: quel rapport à la vie et à la mort, au corps, à la Création, la pratique du jeûne implique-t-elle sur le plan théologique pour les croyants de ces trois religions?

\section{Le jeûne dans le judaïsme}

\section{1 "Une âme sainte dans un corps saint»}

Avant d'aborder la pratique du jeûne dans le judaïsme, soulignons la place centrale qu'occupe le repas dans l'économie de la vie religieuse juive. En effet, plusieurs repas revêtent un caractère d'obligation: c'est le cas des trois repas sabbatiques, de celui qui suit la cérémonie de la Circoncision ou du Rachat du premier-né, de celui de la célébration d'une bar-mitsva ou d'un mariage. La veille du jeûne de Kippour, l'acte de manger se trouve être aussi méritoire et contraignant que l'abstention de toute nourriture le lendemain, ce repas étant destiné à assurer au corps une meilleure résistance lors de l'épreuve du jeûne à venir (Gugenheim 1978, 54). Comment expliquer que tantôt le jeûne, tantôt le repas revêtent un caractère d'obligation? Quelle est donc la fonction de ces commandements?

D'après Gugenheim, il s'agit, à travers le respect des commandements religieux et des défenses alimentaires non pas de nier l'importance du matériel, mais de le sublimer: "une âme sainte dans un corps saint " (Gugenheim 1978, 54). De plus, le respect des défenses alimentaires permet au croyant d'exprimer, de traduire en actes, sa soumission à Dieu. Ainsi, le seul commandement qu'Adam ait reçu porte sur la manducation d'un arbre $^{2}$. Puis Noé s'est vu, au sortir de l'arche, interdire la consommation du sang et d'un membre d'animal encore vivant: les lois alimentaires qui sont venues réglementer la vie du peuple de Dieu permettent au croyant d'exprimer sa soumission à Dieu (Gugenheim 1978, 55).

Enfin, dans cette vision sémitique du monde, les règles alimentaires permettent de distinguer le pur de l'impur: l'homme qui ne les observe pas

2. Gn 2,17a: «Mais de l'arbre de la connaissance du bon et du mauvais, tu n'en mangeras pas. » (trad. Olivier 2009, 11). 
devient dans cet état «semblable à la bête, prisonnier de la matière, plongé dans les plaisirs grossiers de ce monde» (Luzzatto 1956, 76).

La prescription du jeûne se trouve, elle aussi, au nombre de ces défenses: son respect permet au croyant de sanctifier ce corps, cette vie, d'exprimer sa soumission à Dieu, de se purifier. Pourtant, chacun des jeûnes prescrits revêt une signification bien particulière. Ce n'est qu'en référence à l'histoire sainte du peuple juif et aux Écritures que le sens de chaque jour de jeûne peut réellement être saisi.

\subsection{Le jê̂ne, signe d'affliction et d'humilité}

Le premier jour de jeûne institué par la Torah est celui du Yom Hakippourim (le Jour des recouvrements), également appelé "Yom Kippour », le Jour du Pardon. D’après le Lévitique (16,30-31; Lv 23,27-32), en ce jour, il sera fait recouvrement de toutes fautes devant l'Éternel: chabbat, jour de repos, ce jour-là «vous humilierez vos personnes » ${ }^{3}$ : «innah nafcho ». Dans cette expression, en hébreu, la racine A.N.H., qui est aussi celle du mot "ani », "pauvre", indique qu'il s'agit, à travers l'observance du jeûne de s'appauvrir, de prendre la condition de l'indigent (Haddad 2006). Il convient ce jour-là de priver sa personne de tout ce qui peut en faire l'agrément et l'orgueil. On s'abstient également de se baigner, de s'oindre, de se chausser de cuir et d'avoir des relations conjugales. La pratique biblique du jeûne manifeste ainsi l'affliction: bien souvent, la personne qui jeûne remplace son vêtement par un sac, se couvre de cendres et ne salue personne (Jon 3,6-8; Is 58,5; Dn 9,3; Est 4,3; 1 R 21,27). Signe de pauvreté intérieure, le jeûne, tout comme l'aumône et la prière, permet d'implorer le pardon des péchés (Vajda 1938, 368).

\subsection{Le jeûne de commémoration}

Le temps du jeûne est aussi un temps de commémoration des tragédies vécues par Israël: ainsi, le jeûne du 17 Tammouz commémore la prise de Jérusalem et son siège (Jr 39,1-2; Jr 52,4-7), celui du 9 Av est observé en souvenir de la destruction du Premier Temple (586 av. J.-C.), de celle du Second Temple (70 ap. J.-C.) et des exils qui s'en suivirent (TJ Ta 'anit, IV,1). Le jeûne du 3 Tichri, rappelle aux croyants l'assassinat de Guédalia fils d'Ahiqam (Jr 41,1-2; TJ Ta'anit IV, 5; DM, 394). Celui du 10 Tévet

3. Traduction Haddad (2006). 
est observé en mémoire du jour où Ézéchiel et les juifs captifs apprirent la ruine du Temple. Il rappelle aussi le siège de Jérusalem par Nabuchodonosor (Jr 52,4; 2 R 25,1-2; Ez 24,1-2; TJ Ta anit IV,5). Récemment, ce jour de jeûne a été choisi pour réciter le Qaddich pour les victimes de la Shoah dont on ignore la date de décès (Bauer 2011, 339). Enfin, le jeûne des «Premiers-Nés » commémore le deuil des premiers-nés égyptiens morts dans le processus de libération du peuple hébreu et le salut miraculeux des premiers-nés israélites (Ex 11,2-7; 12,29; DEJ, 577; Noyé 46).

Le jeûne commémoratif, en faisant mémoire d'un événement collectif, permet d'éprouver dans son corps la réalité d'une histoire sainte. La réalité d'hier demeure, par l'anamnèse, toujours présente: elle est réalité actuelle (Meslin 1988, 145-146). Jeûner, c'est communier, se relier à une mémoire partagée, affirmer que l'on éprouve une même conscience de l'histoire.

\subsection{Le jeûne de prière et le jêิne de purification}

Le jeûne prépare et accompagne la rencontre avec Dieu : ainsi Moïse jeûne quarante jours à l'occasion du don de la Loi (Ex 34,28); Elie marche quarante jours en direction du mont de la rencontre avec l'Éternel grâce à la force reçue d'un seul pain (1R 19,8); au terme de trois semaines de stricte abstinence, Daniel reçoit la visite, près du Tigre, d'un être au visage de feu qui lui révèle les mystères des jours derniers (Dn 10,2-3): l'observance du jeûne permet de se préparer à recevoir une révélation ou une vision (Goitein 1966, 152).

Dans le judaïsme post-biblique, le jeûne public en temps de sécheresse, de pestilence ou d'autres calamités, est imposé par les autorités rabbiniques, comme en témoigne le traité Ta anit du Talmud (Rouleau des jeûnes), consacré à cette pratique (Goitein 1966, 152; Greenstone 1945, 4). La pluie engendre la récolte, la récolte est synonyme d'abondance, l'abondance est promesse de vie. Le jeûne n'est pas ici synonyme de renoncement à l'égard du monde: il est tourné vers l'espérance de la récolte. Il est une prière adressée à Dieu, dont "la sainteté est assimilée à une force de vie» (Duhaime 1998, 26).

Le jeûne de prière est illustré par celui que la reine Esther demanda à ses coreligionnaires d'observer lors de son intercession en leur faveur auprès du roi (Est 4,15-17). Sa victoire est fêtée le jour de Pourim; la veille est un jour de jeûne, en souvenir du jeûne d'Esther (Noyé 2007, 44-45).

La tradition juive semble suggérer qu'une prière vraiment insistante ne saurait être faite sans jeûner (Jdt 4,13). Le jeûne peut également être 
observé pour implorer Dieu de permettre la guérison d'un être cher, à l'instar du Roi David jeûnant dans l'espérance de la guérison de son enfant (2 S 12,22-23). Le jeûne purifie et apaise: il est conseillé de jeûner après un cauchemar afin de retrouver la paix de l'esprit. Enfin, le jour de leur mariage, les époux jeûnent afin d'expier leurs péchés au moment de commencer une nouvelle vie (Goitein 1966, 152; DEJ, 576).

Depuis peu est apparue une nouvelle forme de jeûne qui s'inspire du jeûne de prière: le jeûne militant, pour demander justice. Ainsi le jeûne d'Esther a revêtu récemment une nouvelle signification: sous l'égide de la Coalition Internationale pour les droits des Agounot (ICAR), des milliers de femmes juives ont choisi de jeûner la veille de Pourim afin de signifier leur solidarité avec les femmes agounot, en attente de leur divorce religieux (guet), ce dernier ne pouvant être remis que par l'homme (Lipsyc 2011; Süsskind-Goldberg 2007, 207). Jeûner, c'est ici prier, mais aussi demander justice, priver son propre corps, pour obtenir justice.

\subsection{Valeur morale et spirituelle du jê̂ne}

En souvenir des quarante jours de jeûne que Moïse observa pour obtenir le pardon des Israélites, coupables d'avoir adoré le veau d'or (Vajda 1938, 377), le jeûne de Kippour est repentance et doit nécessairement être précédé par la réconciliation, faute de quoi il est inefficace (Haddad 2006). À l'occasion de Yom Kippour, les rabbins lisent souvent le passage suivant qui insiste sur la valeur édifiante et morale du jeûne (Greenstone 1945, 4): "Voici le jeûne auquel je prends plaisir: détache les chaînes de la méchanceté, dénoue les liens de la servitude [...]; partage ton pain avec celui qui a faim, et fais entrer dans ta maison les malheureux sans asile [...]; après quoi il est dit: alors tu appelleras, et l’Éternel répondra [...].» (Is 58,6-7; TJ Ta anit II,1).

Ici, le jeûne ne constitue pas une fin en soi, mais un moyen de renoncer à ses mauvais penchants et d'améliorer sa conduite envers autrui (DM, 395). Il apparaît ainsi que la pratique du jeûne est, dans la religion juive, un devoir religieux, mais les prophètes comme les rabbins ont toujours aspiré à en dépasser l'élément ascétique pour insister sur sa valeur morale et spirituelle (Greenstone 1945, 4).

\subsection{Judaïsme et ascétisme}

L'ascétisme, le dépouillement et l'abstinence ont toujours existé comme valeurs religieuses dans le judaïsme depuis l'époque biblique jusqu'à nos 
jours. Cependant, on peut lire dans le Talmud de Jérusalem que «L'homme sera un jour tenu de rendre compte pour n'avoir pas mangé de ce que l'œil a vu.» (TJ Kiddouchim, IV,14). Se priver des biens accordés par Dieu est une faute. Afin d'analyser la relation du judaïsme à l'ascétisme, il convient tout d'abord de comprendre la manière dont est conçu le corps dans la Bible hébraïque.

Les désignations bibliques de l'humain renvoient d'emblée à son corps. Le nom du premier humain, "l'adam ", dérive du terme hébreu "adama» qui désigne la «terre» ou la "glèbe». L'essence corporelle de l'humain n'est jamais séparée de son esprit dans la Torah. Le concept de néféch ne peut être détaché de sa signification charnelle et de ses fonctions corporelles: il désigne l'âme dans un corps, le corps doté du souffle, l'être vivant doté du souffle, l'être humain dans sa totalité. Il s'agit d'une anthropologie moniste. D'où l'absence de tout mépris du corps dans les sources juives anciennes. Sans être une fin en soi, le corps a une mission à accomplir sur terre, une mission que Dieu lui a confiée (Ruben-Hayoun 2001, 31-34).

Dans l'histoire hagiographique juive, J. Baumgarten confirme l'absence de mépris du corps et constate que parmi les voies menant à la sainteté, l'ascèse y demeure marginale. Alors que le saint chrétien mène un combat contre la chair et tend à discipliner son corps, dans le judaïsme, "l'abstinence, la pénitence, l'ascèse, le renoncement à toute sexualité ne deviennent jamais un but religieux et une condition d'accession au statut social de saint" (Baumgarten 2001, 45n). S'il est parfois fait mention de certaines pratiques, c'est afin de "rechercher un état de concentration et d'intériorisation propice à la communication avec le divin et au tikkun ${ }^{4}$ (Baumgarten 2001, 83).

La tradition juive met volontiers en garde contre les excès de zèle en matière de mortification. Il est question dans le Livre des Nombres (6,121) du vœu de naziréat, observé notamment par Samson (Jg 13,3-7; 16,17) ou encore par Samuel (1 S 1,11). Il est interdit au nazîr de boire du vin ou une autre boisson à base d'alcool, de tirer le moindre profit d'un produit de la vigne, de se couper les cheveux, ou de s'approcher d'un mort, et donc d'un cimetière (DEJ, 724-725). Ce vœu permet d'éviter l'excès de zèle, jugé condamnable, car c'est dans la tempérance que l'humain peut exprimer son amour de Dieu (Haddad 2006). Une pratique ascétique trop sévère n'est pas encouragée: «Pour le juif, l'état normal, naturel, est la santé. La maladie le soustrait à l'observance régulière des pratiques. Les actes matériels

4. Dans le vocabulaire de la mystique juive, la réparation ou la restauration. 
qu'il accomplit, tels que manger et dormir, ont pour but de le rendre mieux apte au service de Dieu : ils deviennent alors des mitsvoth [des commandements]»(Gugenheim 1978, 54).

Ainsi, la pratique du jeûne ne doit pas mettre en péril la vie ou la santé: les femmes enceintes et celles qui allaitent, les malades ainsi que les enfants n'ayant pas encore atteint l'âge de la bat- et bar-mitsva sont dispensés de jeûner (DB, t.3, 1532; DM 394). La tradition juive invite à s'éloigner de la mortification car l'être humain tout entier, corporellement et spirituellement, est au service de Dieu (DM, 396).

Pour le théologien Saadia Ga'on (m. 942, Bagdad), l'ascèse consiste en une prudente réserve et une sobriété précautionneuse dans l'usage que l'on fait des moyens de subsistance, des biens de ce monde et des plaisirs charnels que comporte la normale condition humaine (Vajda 1964, 40). Quant à l'Andalou Bahya ibn Paqûda (m. v.1080), il écrit que l'humain doit réparer ses fautes par la pénitence qui est accomplie grâce à la contrition, au renoncement au péché. La vie intérieure, qui consiste en un examen de conscience continuel et une soumission à la volonté de Dieu, n'implique cependant pas une rupture totale avec le siècle (Vajda 1947, 93).

Pour Moïse Maïmonide (m.1204), la quête de la vision béatifique implique un détachement qui consiste à être constamment tourné vers Dieu et à toujours demeurer uni à Lui, tout en maintenant l'activité extérieure et les relations avec les hommes (Vajda 1947, 143, 145). Dans Le Guide des égarés, il écrit:

[...] lors même que tu serais l'homme le plus savant en vraie métaphysique, si tu détournes ta pensée de Dieu et si tu t'occupes tout entier de ta nourriture ou d'autres affaires nécessaires, tu as coupé ce lien qui existe entre toi et Dieu. [...] David a dit: «Je place l'Éternel constamment devant moi, car il est à ma droite et je ne chancellerai pas» (Ps 16, 8); cela veut dire: Je ne détourne jamais ma pensée de Dieu.» (Maïmonide 2003, III, 51, p. 619)

Moshe Idel interprète ainsi ce passage: la faute d'Adam est non seulement sa désobéissance à une simple interdiction mais aussi et surtout sa tolérance donnée à l'imagination et aux plaisirs des sens. C'est pourquoi, le fait de devenir capable de fixer ses propres pensées sur la "science divine» (la métaphysique) quel que soit le genre d'actes corporels que l'on effectue, permet à de rares individus de retourner à l'état d'avant la chute (Idel 1991, 95).

Obadyah Maïmonide (m.1265), petit-fils de Moïse Maïmonide, écrit dans son Traité du puits: "[...] si tu détaches tes pensées des jouissances 
physiques, te tournant vers Dieu de tout ton cœur et ne t'éloignant pas de Sa porte, alors tu seras délivré de l'imperfection et des accidents du monde ici-bas.» (Fenton 1987, 26b, 188).

Ainsi, pour l'ensemble de ces auteurs, le jeûne ne se justifie pas par le mépris du corps: il est un moyen parmi d'autres de se perfectionner spirituellement et de parvenir ainsi à la vision béatifique et à la contemplation divine. Selon Vajda, l'ascèse n'est, dans l'histoire du judaïsme, qu'une voie extraordinaire, un remède héroïque et exceptionnel. Elle n'est pas un chemin d'accès indispensable au salut. L'idéal de vie le plus authentique dans le judaïsme est celui qui ne s'écarte pas de «l'équilibre requis par la Loi révélée» (Vajda 1964, 43).

\subsection{Le jeûne dans les camps}

Cynthia Haft a rapporté les débats qui avaient lieu dans les camps de concentration au sujet de l'observance du jeûne de Kippour: "Fallait-il jeûner? La question était âprement débattue. Jeûner pouvait signifier une mort plus certaine, plus rapide. On jeûnait ici toute l'année. Toute l'année, c'était le Yom Kippour» (Haft 1973, 46). Certains décidèrent de ne pas jeûner afin de ne pas mettre leur vie en péril. D'autres décidèrent de jeûner afin de "montrer à Dieu que même ici, dans cet enfer clos, on était capable de chanter Ses louanges » (Haft 1973, 46). Cependant, selon Haft, ce choix était surtout motivé par le désir d'affirmer sa dignité humaine. Si le détenu choisissait de jeûner, c'était afin de "conserver l'image qu'il avait de luimême, pour demeurer celui qu'il était avant d'arriver au camp » (Haft, 1973, 46-47). Le jeûne devenait alors, pour les détenus, une manière de préserver l'image qu'ils avaient d'eux-mêmes, leur "Moi ». Jeûner, c'était choisir librement de se priver de nourriture, bien que l'on soit incarcéré. Ici, il ne s'agit pas de se laisser mourir, mais, «dans cet enfer clos », d'affirmer sa dignité humaine, de sanctifier ce corps, cette vie.

Cet exemple montre bien qu'il ne s'agit donc pas, à travers l'observance du jeûne, de mépriser ce corps, ou de renoncer à cette vie: il s'agit de les sanctifier. Jeûner, c'est «chanter Ses louanges ».

\section{Le jeûne dans le christianisme}

S'inscrivant à la fois en continuité et en rupture avec la religion juive, le christianisme s'en distingue et innove, concernant les champs de la théologie et de la pratique. Quelles sont les implications théologiques du jeûne 
dans la religion chrétienne, quelle relation au corps, à la Création, à la vie et à la mort implique-t-il ?

\subsection{Une référence fondatrice: les quarante jours du jê̂ne mosaïque}

Lorsque Jésus jeûne au désert, il répond au Tentateur qui lui propose de transformer une pierre en pain: "Ce n'est pas seulement de pain que l'homme vivra» (Lc 4,1-4). Jésus annonce que l'humain est invité à découvrir la part divine en lui, à se nourrir non seulement de pain, "mais de toute parole sortant de la bouche de Dieu» $(\mathrm{Mt} 4,4)$.

À la différence de Jean-Baptiste, le nazîr, qui ne boit ni vin ni liqueur fermentée, ascète reclus vivant hors la cité, Jésus, après avoir jeûné au désert, part affronter le monde afin d'y proclamer la Bonne Nouvelle. Les Évangiles nous le présentent buvant du vin et ne respectant pas les interdits alimentaires judaïques (Perrot 1993, 107). Les disciples de Jean jeûnent, non ceux de Jésus (Lc 5,33-35).

Ainsi, peu avant sa mort, Jésus révèle à ses disciples une autre signification du jeûne (Lc 5,33-35). Cette pratique, qui dans la religion juive traduisait l'affliction de l'âme, exprimera désormais l'in-satisfaction de l'âme en l'absence du Christ, qui est le Logos, le Verbe fait chair, la Parole divine incarnée.

Cependant, selon Carla Noce, la lecture des synoptiques porte à croire que Jésus n'aurait pas considéré le jeûne comme une forme préférentielle d'intégration sociale. Il semble avoir privilégié l'acceptation de la nourriture d'autrui en contexte collaboratif: manger ensemble entre amis, riches, pauvres, justes et injustes, préfigure le Royaume de Dieu (Noce 2011, 60-61).

\subsection{Ascèse païenne et ascèse chrétienne}

Pourtant, l'Église primitive va être caractérisée par l'austérité de ses ascètes: au cours des $\mathrm{III}^{\mathrm{e}}$ et $\mathrm{IV}^{\mathrm{e}}$ siècles, cénobites, ermites et anachorètes accomplissent des "performances » ascétiques. Derrière l'éloge chrétien du jeûne, moyen d'apaiser le désir, de purifier le corps et de promouvoir l'esprit, peut être décelée l'influence d'une pensée néoplatonicienne, un désir d'échapper au corps qui tire sans cesse l'esprit vers le bas (Bynum 1994, 62-64). Assouly observe que "L'ascète transforme son corps en une offrande, paie de sa personne sans sacrifier son existence». Pour lui, son projet «se résume à la ruine du corps de manière à libérer l'esprit du joug 
charnel ». Dès lors, se demande-t-il, « la pacification religieuse ne se fondet-elle pas sur une effraction violente à l'endroit du corps? » (Assouly 2002, 194-195).

Toutefois, la lecture attentive des règles monastiques montre que contrairement au rêve de Porphyre d'une abstinence totale permettant d'atteindre la pure vie de l'esprit, la pratique monastique du jeûne se confond rarement avec le désir d'épuiser ou d'exténuer le corps (Vuillaume 1989, 46). Pour la majorité des Pères de l'Église, la mortification excessive ne mène pas à Dieu, mais détruit le corps et l'esprit. La signification du jeûne des moines et des ascètes chrétiens ne se comprend qu'en référence à celui du Christ rédempteur: le jeûne assume une fonction pédagogique vis-à-vis du corps. Il devient un instrument de domination des passions et permet au chrétien d'expérimenter de manière tangible la transformation que le Christ opère en lui (Noce 2011, 159). La majorité des traditions ascétiques chrétiennes des premiers siècles sont traversées par une idée commune: le rôle fondamental assigné au corps dans la réalisation du salut (Noce 2011, 162).

\subsection{Le premier Adam}

Selon le pape copte orthodoxe Shenouda III (m. 2012), la prescription du jeûne fut la première que Dieu donna à l'être humain. En interdisant à Adam de manger du fruit de l'arbre de la connaissance du bien et du mal (Gn 2, 16-17), Dieu imposa certaines limites à l'absolue liberté humaine (Shenouda III 1990, 9-10).

Comme l'observe Dom Vuillaume, "l'Écriture n'a pas choisi d'autre représentation que celle d'une manducation illégitime pour traduire le mystère du mal et de la souffrance» (Vuillaume 1989, 54). Cette lutte spirituelle contre le péché de gourmandise se justifie dans une perspective théologique qui prend ses origines dans la Genèse. Pour le cistercien Alain de Lille (m.1202), "s'il avait jeûné au paradis [...], Adam n'en aurait pas été chassé, puis damné; s'il avait jeûné [...], Ésaü n’aurait jamais perdu son droit d'aînesse; s’il avait jeûné [...], Noé n'aurait pas souffert dans sa pudeur» (Bynum 1994, 70). Le jeûne s’inscrit dans un projet sotériologique dont le point de départ est le constat d'un déséquilibre:

Divisé contre lui-même [...] l'être humain est en réalité le terrain et l'objet de la lutte continuelle que se livrent la chair (caro) et l'esprit (spiritus). L'effort ascétique a donc pour but de maintenir ou de rétablir la prédominance de la réalité spirituelle sur la chair et d'assurer ainsi le salut de l'âme 
[...] Exprimé en termes de guérison, le salut consiste alors à établir la dilectio en son objet véritable ou encore à ré-orienter le désir qui meut la volonté. (Vuillaume 1989, 52-53)

D'une manière comparable, le Kitâb al-hudâ maronite, traduit du syriaque à l'arabe au XI ${ }^{\mathrm{e}}$ siècle, enseigne que le jeûne a été institué par Dieu comme un remède aux conséquences de la désobéissance d'Adam, qui a consommé une nourriture illicite. L'observance du jeûne y apparaît comme un effort pour restaurer l'harmonie entre le corps et l'ordre de la création (Heyberger 2006, 272).

\subsection{Le "second Adam» et le sens pascal du jềne}

Au cours du Carême pré-pascal, le jeûne est rompu en célébrant la présence du Christ ressuscité: il traduit l'in-satisfaction radicale du chrétien en l'absence de son Seigneur. En entrant dans le processus pascal du jeûne, le croyant «se situe en tension vers la plénitude de son être encore inachevé » (Vuillaume 1989, 60).

Les cendres dont les juifs se couvraient lorsqu'ils jeûnaient étaient signe d'humilité et d'affliction. Celles que le chrétien reçoit sur le front le premier jour du Carême rappellent à l'humain qu'il n'est que poussière et cendres et redeviendra poussière. C'est par la voie de cette humilité que le corps de l'humain, lieu de la désobéissance, va devenir lieu de l'obéissance (Vuillaume 1989, 57). Le corps, lieu de la chute, devient le lieu d'un procès de conversion évangélique. Le jeûne devient alors l'instrument de la Rédemption.

\subsection{Jeûne de préparation et de purification}

Le jeûne peut aussi être observé à des fins de purification comme en témoigne la pratique du jeûne pré-baptismal (Noce 2011, 85-87; Goguel d'Allondans 1998, 116), celle du jeûne observé à l'occasion de l'ordination des prêtres (Noce 2011, 95; Shenouda III 1990, 16) ou encore celle du jeûne eucharistique, qui vise à purifier celui qui s'apprête à recevoir le corps du Christ (Heyberger 2006, 269). Dans ce dernier cas, le jeûne a une fonction de purification: il précède le repas. Le Kitâb al-Hudâ maronite définit les modalités de ce jeûne, qui vise à placer le croyant en état de pureté avant de recevoir «le Corps pur» du Christ (Khoury 1966, 256271). Ces règles révèlent une conception sémitique du monde, du corps, des notions de pureté et d'impureté. 
Au cours des premiers siècles de l'ère chrétienne, le Carême est d'une grande rigueur: les auteurs musulmans nous apprennent qu'au viI ${ }^{\mathrm{e}}$ siècle, les chrétiens ne rompent le jeûne carésimal qu'une fois dans la soirée, puis s'abstiennent de boisson et de nourriture jusqu'au lendemain soir. Selon un hadîth rapporté par Țabarî, il leur était interdit durant un mois entier d'avoir commerce avec leurs femmes (Vajda 1938, 371). Cette coutume d'un unique repas quotidien pendant le Carême s'est maintenue dans toutes les Églises en Orient jusqu'à une époque récente (Heyberger 2006, 271). En Orient, pendant le Carême, la viande et les produits d'origine animale sont bannis: cette abstention traduit notamment une aspiration à libérer l'animal de l'emprise humaine et à restaurer l'harmonie avec l'ordre de la création, telle qu'elle existait avant la chute (Heyberger 2006, 272; Kanafani-Zahar 2006, 291). La rigueur des jeûnes orientaux est soulignée par les missionnaires européens qui, à partir du XVII ${ }^{\mathrm{e}}$ siècle, viennent prêcher en Orient (Heyberger 2006, 270).

\subsection{Du jềne à la confession}

Mais tandis qu'au Proche-Orient des jeûnes nombreux et rigoureux étaient encore observés jusqu'à une époque récente (Kanafani-Zahar 2006, 289; Ollivry 2006, 166), les premiers moines latins prirent dès le haut Moyen Âge leur distance par rapport à la mentalité des anachorètes et des cénobites d'Orient. La notion d'impureté ou de contamination par des nourritures illicites, la distinction pur/impur, héritée de l'Antiquité juive, va disparaître en Occident (Heyberger 2006, 268-280; Vuillaume 1989, 48).

$\mathrm{Au} \mathrm{XIII}{ }^{\mathrm{e}}$ siècle, Thomas d'Aquin écrit que si l'appétit naturel vient combler la faim et la soif, il existe un autre appétit, qui est un dérèglement: le vice de gourmandise. Cette convoitise désordonnée des aliments souille l'esprit de l'humain et consiste essentiellement en un plaisir immodéré dans le manger et le boire (Harrus-Révidi 1994, 67-68). Selon Assouly, le christianisme a comblé l'absence de produits interdits que connaissait le judaïsme par un renforcement des restrictions concernant le plaisir de se nourrir. "À défaut d'interdire un aliment, la possibilité d'en jouir in extenso est moralement exclue» (Assouly 2002, 143).

Dès lors, l'interdit porte sur le sujet lui-même: le monde extérieur n'est plus divisé en catégories licites et illicites. C'est dans le cœur du croyant lui-même que se trouvent les passions qui doivent être maîtrisées. Ainsi, alors qu'en Orient le jeûne demeure la principale pratique pénitentielle, son équivalent devient en Occident la confession auriculaire, qui se généralise 
à partir du XIII ${ }^{\mathrm{e}}$ siècle: la faute et le pardon sont intériorisés et la pénitence s'effectue grâce à l'examen de conscience (Heyberger 2006, 276).

Harrus-Révidi analyse ainsi ce déplacement: le corps n'est plus, physiquement, le réceptacle du sacré. Tandis que, dans le judaïsme, l'interdit religieux portait sur l'alimentation, l'Évangile annonce que «Ce n'est pas ce qui entre dans la bouche qui rend l'homme impur; mais ce qui sort de la bouche, voilà ce qui rend l'homme impur» (Mt 15,10-11). Pour la psychanalyste, "ces mots restituent à l'homme la responsabilité de l'assomption de son discours »: " quelque chose de l'ordre du libre arbitre commence à poindre». "L'hérésie n'est plus dehors, ingérable tout comme le sacré, mais à l'intérieur de soi » (Harrus-Révidi 1994, 65-66). Il ne s'agit plus du contrôle de l'alimentation mais du contrôle de soi.

Ce principe a été porté à son aboutissement par Martin Luther, qui écrit $\mathrm{au} \mathrm{XVI} \mathrm{I}^{\mathrm{e}}$ siècle: "Il faudrait encore qu'au sujet des jeûnes on s'en remette au bon vouloir de chacun et que l'on puisse librement toucher à toutes les nourritures, ainsi que le permet l'Évangile» (Luther 1999, 644; voir Mt 15,11). L'abolition du jeûne institué, obligatoire et ritualisé va de pair avec un accroissement de la liberté et de la responsabilité du sujet visà-vis de ce qu'il choisit de manger ou de ne pas manger.

\subsection{Jeûne et non-violence}

Si la pratique carésimale du jeûne traduit depuis des siècles un désir de retrouver l'harmonie avec la Création (Heyberger 2006, 272; KanafaniZahar 2006, 291), sa signification s'est enrichie récemment grâce à l'émergence des concepts de «non-violence» et de «conscience écologique».

En effet, le jeûne est un moyen de prendre conscience et de témoigner du fait que l'humain n'est pas propriétaire mais usufruitier des biens dont il dispose pour se nourrir. Lorsque, par ascèse, le croyant renonce à se comporter en propriétaire exclusif ou égocentrique, il se fait, par éthique, le collaborateur du projet divin, en faisant droit à la «justice de Dieu». Le jeûne devient ici un moyen de répartir justement les biens de ce monde et de rétablir l'ordre social en résorbant la pauvreté (Vuillaume 1989, 65-66).

Le jeûneur refuse de consommer, c'est-à-dire de détruire pour son profit personnel, les aliments dont dispose la collectivité: il réduit au minimum son emprunt et sa participation à ce qui est la matière (Vuillaume 1989, 67). Réduire son empreinte en vue d'une meilleure répartition des richesses: telle est aussi l'une des significations du jeûne pour le climat instauré par la Fédération Luthérienne Mondiale en 2014. L’observance 
d'un jour de jeûne mensuel permet d'exprimer sa solidarité avec les personnes affectées par les changements climatiques et d'exprimer sa préoccupation à l'égard de l'empreinte humaine sur terre. Il peut être exprimé sur les médias sociaux grâce au mot-clic: "\#Ifastfortheclimate», geste destiné à accroître une prise de conscience mondiale au sujet de la justice climatique (Sinn et al. 2013).

Par l'ascèse du jeûne, l'être humain apprend à limiter et à gérer sainement ses désirs. Au xx $x^{\mathrm{e}}$ siècle, Lanza Del Vasto souligne, quant à lui, le fait que l'acte de manger s'opère toujours au détriment d'un autre vivant: «Manger, c'est toujours se préférer à l'autre»(Del Vasto 1945, 56). À travers la mise à distance qu'opère le jeûne, ce que l'humain avait tendance à considérer comme un dû, lui apparaît comme un reçu (Vuillaume 1989, 74). L'ascèse, en établissant une distance entre l'être humain et la nourriture que son désir convoite, empêche l'être humain de se perdre en l'objetmême de ce désir.

Le jeûne devient ici un instrument qui permet à l'être humain de retrouver sa place dans le projet divin. Selon Dom Vuillaume, cette place est celle d'une créature appelée à couronner la Création, non à s'y perdre dans l'indistinction (Vuillaume 1989, 75).

La signification spirituelle du jeûne s'enrichit au $\mathrm{Xx}^{\mathrm{e}}$ siècle grâce à un détour par l'hindouisme avec l'exemple de Gandhi: par le jeûne, le Mahatma s'est efforcé de mettre en œuvre le Satyâgraha, principe de nonviolence et de défense de la vérité, en vertu duquel l'ascèse est employée afin de réaliser une adéquation de soi à la vérité en s'infligeant à soi-même la violence que «la nature» nous porterait à infliger à l'autre. Pour cet hindou qui avait, dans sa jeunesse, été sensible au message du Sermon sur la Montagne (Devret 1967, 10, 31), jeûner signifie aussi tendre l'autre joue. Le jeûne est ici un désarmement volontaire dans lequel le corps se nourrit de la puissance de l'esprit qui revendique une vérité. L'exemple de Gandhi inspire de nombreux "jeûnes protestataires ", ou "grèves de la faim ", parfois dénués de toute dimension religieuse à l'époque moderne ${ }^{5}$. Il inspire aussi certains chrétiens, tel Louis Massignon (m.1962), qui devient président des Amis de Gandhi en 1954. Le savant prendra l'engagement de plusieurs jeûnes visant à protester contre les violences subies par les musulmans du Maghreb (Pénicaud 2010, 67) et demandera à Pie XII

5. Nous n'abordons pas ici la dimension politique du jeûne ni la question des «grèves de la faim» et renvoyons à Siméant (2009). 
de bénir le vœu des membres de la Badaliya ${ }^{6}$ de jeûner chaque premier vendredi du mois, en esprit de compassion avec les âmes musulmanes (Massignon 2011, 89-90). Louis Massignon élargit bientôt le cercle du «Notre Père» aux croyants israélites, et s'associe par le jeûne, en accord avec Martin Buber, au Yom Kippour pour une paix sereine au ProcheOrient (Massignon 1997, 189; Pénicaud 2010, 67).

Enfin, le jeûne, parce qu'il affaiblit physiquement le corps charnel, désamorce la colère et purifie le cœur. Son observance est la traduction physique de ces mots du prieur de Tibhirine, Christian de Chergé: «Désarme-moi, désarme-nous, désarme-les» (Müller 2010, 102). Désarmement, renoncement, abandon d'un acte, prière silencieuse et continue, le jeûne s'inscrit dans la réalité même du corps, qui devient alors physiquement le lieu de l'invocation, le lieu d'un travail et d'une conversion du cœur.

Il ne s'agit pas, dans la pratique non-violente du jeûne chrétien, de détruire le corps, de le mépriser ou de l'affamer jusqu'à mourir d'inanition: le jeûne est ici un outil, un levier, qui fait du corps le lieu-même, l'instrument, de la rédemption, de la justice ou de la réconciliation. Il est vécu en esprit d'Imitatio Christi, d'imitation du second Adam, et puise sa signification dans la théologie de l'Incarnation.

\section{Le jeûne en islam}

«Le jeûne vous a été prescrit, comme à vos devanciers (Qur 2,183)»: par ces mots, le discours coranique invite à lire les prescriptions du jeûne du mois de Ramaḍ̂n en référence aux prescriptions antérieures. L'observance du jeûne en islam s'inspire de certaines pratiques juives et chrétiennes, et innove à son tour: quelles sont ses implications théologiques? Quelle relation au corps, à la vie et à la mort implique le jeûne en islam?

\subsection{Le jeûne du Ramadân et la révélation coranique}

"Quand le mois de Ramaḍan commence, les portes du Jardin paradisiaque s'ouvrent, les portes du Feu infernal se ferment et les démons sont enchâ̂nés ", dit un hadîth rapporté par Abû Hurayra (Al-Ghazâlî 2001, 105). Selon Goitein, les motifs présentés par ce dit prophétique sont comparables à ceux de la liturgie juive du jour de l'Expiation (Goitein 1966, 161).

6. Sodalité de prière en esprit de substitution et de compassion avec les âmes musulmanes fondée par Massignon et Kahîl. 
D'après la tradition, le Ramaḍân est une période bénie: "Son commencement est miséricorde, son milieu pardon, son terme affranchissement du feu» (DC, 729).

Moïse reçoit les Tables de la Loi après avoir jeûné quarante jours. D’après la Sîra, Muḥammad reçoit la première révélation durant le mois de Ramaḍân. Dans la sourate 2, un parallèle peut être discerné entre la révélation mosaïque et la révélation coranique: le jeûne est la théophanie dans laquelle Dieu manifeste Sa grâce et Sa miséricorde et révèle aux êtres humains Sa Parole (Goitein 1966, 161-162).

«Ramaḍân» est le seul mois de l'année qui se trouve nommé dans le texte du Coran (DC, 728). D'après la Sîra, c'est au cours d'une nuit du mois de Ramaḍ̂n de l'an 610 que le Prophète Muhammad reçoit pour la première fois la Parole divine que lui transmet l'ange Gabriel, alors qu'il effectue une retraite dans une grotte située sur les flancs du mont Ḥira (DC, 728).

Un hadîth rapporté par Bukhârî affirme que Gabriel vient à la rencontre du Prophète chaque nuit du mois de Ramaḍân pour lui enseigner le Coran, établissant lui aussi un lien entre le mois de Ramaḍ̂n et la révélation coranique (Bukhârî, Șahîh, 6).

On peut lire dans la sourate 2, qui contient les prescriptions du jeûne de Ramaḍân: "Le mois de Ramaḍân dans lequel (fî̀-hi) le Coran a été révélé $[\ldots]$ (... (Qur 2,185). Ibn 'Arabî (m.1240) commente ainsi ce verset: selon lui, le vocable $f \hat{\imath}-h i$ (dans lequel) se rapporte ici, non pas au mois de Ramaḍân, mais au jeûne qui l'accompagne: «dans lequel », c'est-à-dire «dans le jeûne duquel ». Pour Ibn 'Arabî, le Coran est descendu au moyen du jeûne durant la «Nuit du Décret» (Laylat al-Qadr): le jeûne du mois de Ramaḍ̂n et la révélation du Coran apparaissent à Ibn 'Arabî, comme les deux faces d'une unique et même réalité (Ibn 'Arabî 1996, 33-4).

Selon un hadîth rapporté par Bukhârî (m. 870), celui qui prie au cours de la «Nuit des Décrets", en toute sincérité, confiant dans la récompense divine, obtient la rémission de tous ses péchés. Ce lien entre le Ramaḍân, la révélation coranique et la miséricorde divine s'exprime en la pratique des tarâwîh, ces séances de prières nocturnes qui, dans les mosquées, permettent d'assurer une récitation intégrale du Coran durant ce mois (DC, 729-730; Bukhârî, Șahîh, 35).

Extérieurement, l'observance du jeûne du mois de Ramaḍ̂n implique le respect de certaines règles: le jeûne doit commencer le premier jour du mois, jour identifié grâce à la vision par un témoin oculaire du croissant de la nouvelle lune; l'intention de jeûner doit être renouvelée chaque nuit 
par le croyant; le jeûne doit débuter à l'aurore et être rompu lorsque le soleil disparaît derrière la ligne d'horizon ${ }^{7}$; il comprend l'abstention de toute boisson, de tout aliment, et l'abstinence à l'égard des relations conjugales.

Intérieurement, son observance consiste en l'abstention de toute parole inconvenante ou malveillante, de tout acte susceptible d'éveiller les passions en soi ou chez les autres et implique le devoir d'assistance à autrui (DC, 730; EIS, v. 9, 99; Al-Ghazâlî 2001, Ch. I.). D'après un hadîth, celui qui jeûne en ayant la foi et l'espérance d'une récompense obtiendra le pardon de ses fautes passées (Bukhârî, Șahîh̆, 38).

Le jeûne revêt une dimension sociale: partager le repas de rupture du jeûne (iftâr) avec la famille, les voisins ou les amis permet de resserrer les liens et de vivre cette période de privation dans un esprit de partage et de fraternité. À la fin du mois, lors de la fête de la rupture du jeûne (' $\hat{I} d$ $a l$-Fitrr), les croyants s'acquittent d'une zakât spéciale, aumône "purificatrice ": l'argent économisé grâce au jeûne doit favoriser le partage des biens. Ce mois est un mois d'attention et de compassion à l'égard des plus démunis.

Si l'épreuve de la faim, de la soif et de la faiblesse occasionnée par le jeûne doit permettre de ressentir de la compassion à l'égard des plus pauvres, le jeûne ne doit cependant pas mettre en péril la santé: les personnes souffrantes ou âgées, les femmes qui attendent ou allaitent un enfant peuvent s'en dispenser et s'en acquitter par l'aumône. Les voyageurs et ceux qui accomplissent des travaux pénibles peuvent reporter leurs jours de jeûne à plus tard (al-qad̂â'). Les enfants en sont dispensés jusqu'à l'âge de la puberté: ces prescriptions montrent distinctement que la pratique musulmane du jeûne se veut respectueuse de la santé et de la vie.

\subsection{Confiance et gratitude}

Au x $x^{e}$ siècle, Al-Ḥakîm al-Tirmidhî rapporte un hadîth d'après lequel les gens qui mangent le moins sont les prophètes et les saints (awliyâa), du fait que chaque fois que l'humain reçoit davantage de certitude (yaqîn), il diminue sa consommation de nourriture et le nombre de ses repas (Gobillot 1996, 116). Le "tawakkul", "confiance totale en Dieu» ou "certitude complète», peut en effet se comprendre en référence au nom

7. Selon le droit chi îte, le jeûne ne doit être rompu que lorsque tout rougeoiement a disparu à l'Est de la voûte céleste (Soufi 2012). 
de Dieu «ar-Razzâq» (Qur 51,58), "Celui qui accorde la nourriture ». La tradition rapporte ces paroles du Prophète, aux consonances évangéliques: "Si tu avais confiance en Dieu comme tu le devrais, Il te nourrirait comme Il nourrit les oiseaux» (Schimmel 1996, 155). C'est dans cet esprit que de nombreux ș̂ûîs pensent qu'ils ne doivent pas s'inquiéter de leur subsistance, ni passer trop de temps à chercher leur pain quotidien, ni faire de réserves, ni penser à la nourriture en dehors des repas (FeuilleboisPierunek 2006, 95). Le Coran invite l'humain à grandir dans la confiance en Dieu et rappelle que par le passé, Dieu fit descendre la manne et les cailles sur les croyants en un nuage (Qur 2,57). Après le jeûne, ce mot, manne (ni'ma) était, d'après la Tradition, repris par le Prophète qui disait: "Ô Dieu, pour toi j'ai jeûné, et sur ta manne [ni'matuka] j'ai rompu, la soif est partie, les veines s'humidifient, Dieu est le plus grand» (Kanafani-Zahar 2006, 299). Cette même prière est formulée jusqu'à nos jours par les musulmans au moment de rompre le jeûne. Elle exprime la gratitude et la confiance du croyant à l'égard de Dieu, ar-Razzâq, qui assure à chaque vivant sur terre, sa subsistance.

\subsection{Instrument de libération}

Selon Rûmî (m.1273), les créatures sont de trois sortes: les anges, dont la nature et la nourriture sont l'obéissance et le souvenir de Dieu (dhikr); ensuite les animaux, qui sont pure concupiscence, n'ont ni raison ni obligations; et enfin les pauvres humains, composés de raison et de concupiscence. L'humain serait donc à mi-chemin entre l'ange et l'animal. Alors que l'ange est sauvé par la connaissance, l'animal est sauvé par son ignorance. Entre les deux, l'humain est en litige (Rûmî 1982, ch.17, 108-109). Le salut de l'humain, sa libération, dépend "principalement de son refus de se soumettre aux appétits de son corps et de sa capacité à les dominer » (Benkheira 2000, 199). Le jeûne est donc un instrument de libération. C'est pourquoi il est pratiqué comme initiation à la vie spirituelle. Cette initiation est ressentie par les ș̂ufîs comme une lutte contre l'âme charnelle (nafs), siège des passions et des penchants égocentriques, ou contre le «Soi».

\subsection{Du jeûne du commun au jeûne de l'élite de l'élite}

Abû Ḥ̂mid Al-Ghazâlî (m.1111) distingue le jeûne du commun (șawm al-'umûm), qui est caractérisé par l'abstinence à l'égard des désirs du 
ventre (baṭn) et du sexe (farj), du jeûne de l'élite (șawm al-khuṣ̂șs): celui-ci implique un jeûne du regard, de la langue, de l'ouie et des membres qui doivent s'abstenir de tout péché et sont ainsi amenés à se purifier. De plus, il implique de manger très peu au moment de la rupture du jeûne et de ressentir en son cœur la crainte et l'espoir devant l'incertitude de savoir si le jeûne sera agréé de Dieu (Al-Ghazâlî 2001, 129-152). De même, Rûmî souligne la nécessité d'accompagner le jeûne d'une lutte contre les idoles intérieures auxquelles nous obéissons: la cupidité, les passions, la tempérance et l'envie (Rûmî 1982, 108).

Les premiers ascètes ont souvent été décrits comme qầim al-layl wa şâ'im ad-dahr, "passant leurs nuits en prière, dans une posture droite, et maintenant, pendant le jour, un jeûne perpétuel» (Schimmel 1996, 150). L'épreuve de la faim est souhaitable pour l'ascète qui veut purifier son cœur et se détacher du périssable. Elle s'accompagne de l'observance du silence, de la veille et du choix de la pauvreté (Gramlich 1997, 218-222).

Le jeûne, chez les premiers ascètes musulmans, exprime leur détachement à l'égard de tout le périssable. Affirmation de la transcendance de Dieu et renoncement au monde, l'ascèse est vécue dans l'attrition et la crainte du Jour du jugement (Melchert 1996, 52).

Junayd (m. 911), le maître spirituel de Bagdad, enseigne que le combat qui doit être mené contre les passions vise à cesser de préférer la splendeur fugitive de la "vie immédiate» à ce qui demeure à jamais dans la vie dernière et à rompre les liens qui distraient le croyant de Dieu, comme y invitent les versets Qur 20,131: "Ne porte pas tes regards vers les jouissances éphémères [...]» et Qur 18,28: "Que tes yeux ne se détournent point d'eux par amour de la parure de ce monde! [...]» (Junayd 1983, 97).

L'une des grandes figures de l'hagiographie musulmane, Rabi'a al-'Adawiyya (m. 801), avait atteint un tel degré d'ascèse qu'elle s'abstenait de manger durant toute une semaine, durant laquelle elle priait continuellement sans jamais s'asseoir. Elle disait suivre ce conseil du Prophète: «Rendez vos ventres affamés, vos foies assoiffés et vos corps dénudés, pour que peut-être vos cœurs puissent voir Dieu en ce monde.» Le mystique persan Farîd al-Dîn 'Aț̣âr (m.1229) lui attribue ces vers: "Si tu aspires à souffrir par Allâh, tu dois renoncer à jamais à ce monde. Apprends que tant que l'ici-bas t'occupera, la nostalgie de Dieu ne te visitera pas. » (Annestay 2009, 51, 78, 81-82).

L'abstinence du jeûne ne concerne pas seulement le corps: dans son chapitre consacré aux «secrets du jeûne », Al-Ghazâlî évoque le «jeûne de l'élite de l'élite» (șawm khuṣ̂us al-khuṣ̂uṣ). Ce jeûne consiste à détourner 
son cœur des préoccupations mondaines et de toute autre pensée que celle de Dieu. Il est rompu dès que la pensée se détache de Dieu ou du Jour dernier (Al-Ghazâlî 2001, 130). D’après lui, seuls les Prophètes, les Véridiques et les Rapprochés peuvent le pratiquer. Il rapporte à ce sujet un récit dans lequel Jésus ('Issa), est présenté comme une figure ascétique exemplaire.

On raconte que Jésus passa soixante jours en conversation intime avec son Seigneur, sans manger. Alors la pensée du pain lui vint, et son intimité fut brisée. Aussitôt une tranche de pain apparut dans sa main; alors il s'assit et pleura la perte de l'intimité. À ce moment, l'ombre d'un vieil homme se posa sur lui et Jésus lui dit: "Que Dieu te bénisse, ami de Dieu. Prie Dieu pour moi, car j'étais en extase et la pensée du pain m'est venue, et mon extase s'est rompue ». Le vieil homme fit cette prière: «Ô Dieu! Si Tu sais que la pensée du pain m'est venue depuis que je Te connais, ne me pardonne pas. Au contraire, si quelque chose est apporté devant moi, je le mangerai sans y accorder la moindre pensée.» (Khalidi 2003, 186).

Ici, le péché ne consiste pas à rompre extérieurement le jeûne mais à rompre l'intimité avec Dieu. Pour les mystiques musulmans, les trois niveaux de la rupture du jeûne peuvent être ainsi résumés: le jeûne est rompu selon la Loi (sharî'a), si la personne qui jeûne ingère quelque nourriture, selon la Voie (tarîqa) si elle médit sur autrui, et selon la Réalité (haqîqa) si elle pense à autre que Dieu (Geoffroy 2003, 95).

Être vide de la nourriture de ce monde est la condition préalable à l'illumination. Al-Ghazâlî affirme que la faim purifie le cœur et permet le dévoilement (Al-Ghazâlî 2001, 136). Rûmî demande : la flûte peut-elle chanter si son estomac est plein? (Schimmel 1996, 152). Pour ces mystiques, l'être humain ne reçoit le souffle de l'inspiration divine que lorsqu'il se tient affamé et vide. "Comme les premiers moines chrétiens qui vivaient exclusivement de l'hostie, les saints musulmans considéraient la faim comme la meilleure manière d'atteindre l'état spirituel ", observe Annemarie Schimmel (Schimmel 1996, 152).

Rûzbehân Baqlî (m. 1209) relate l'histoire d'un saint qui avait fait un jeûne total de soixante-dix jours; pendant cette période, il était resté en contemplation devant l'Éternel. Cet état, dans lequel la nourriture lui vient de la Parole, fait écho au verset coranique: "Je reste avec mon Seigneur qui me nourrit et me donne à boire.» (Qur 26,79). Ibn 'Arabî parle lui aussi de la nourriture que Dieu lui octroyait durant la nuit et de sa bonne odeur (Ibn 'Arabî 1996, 31). L'adoration et la lumière divine sont la nourriture de l'homme spirituel et du șûfî (Schimmel 1996, 153). 
En raison de son invisibilité, le jeûne est un secret dont Dieu seul est témoin: Dieu seul peut le récompenser. C'est l'un des sens de ce hadîth $q u d s \hat{\imath}$ : «Tout acte du Fils d'Adam lui appartient à l'exception du jeûne car celui-ci est à Moi et c'est Moi qui le récompense» (Ibn 'Arabî 1996, 12-13). Ce hadîth peut, selon le philosophe andalou, se comprendre en lien avec le nom de Dieu: "al-Qayyûm». Dieu est Celui qui subsiste par Luimême, et pourtant tout existant subsiste par Lui (Gimaret 1988, 189). C'est pourquoi le jeûne vient de Dieu: la transcendance du jeûne n'est qu' «empruntée » à Dieu par le serviteur, et cela de façon passagère et contingente (Ibn 'Arabî 1996, 20).

Le jeûne, n'est pas un acte, mais l'abandon d'un acte (tark). Selon Ibn 'Arabî, le jeûne est dépourvu de toute réalité propre: pure négation existentielle, il n'appartient pas à l'Homme mais tout entier à Dieu (Ibn 'Arabî 1996, 51). C'est pourquoi, selon le Cheikh al-Akbar, le jeûneur est le support d'une théophanie essentielle: il contemple directement ce qui appartient à Dieu et c'est Lui qui est sa récompense (Ibn 'Arabî 1996, 17). Le jeûne initiatique est "stupeur muette ", contemplation de l'Essence divine: alors que la prière rituelle peut être comparée à un entretien avec Dieu, ce qui implique parole et compréhension, le jeûne est contemplation. La prière est un voile et le jeûne un dévoilement (Ibn 'Arabî 1996, 17-18).

Pratique permettant d'éprouver de la compassion à l'égard du pauvre, de mieux dominer les appétits du corps, de se détacher du périssable, le jeûne est un instrument d'initiation à la vie spirituelle. Pour le croyant musulman, choisir l'absence de repas, c'est choisir de s'éloigner de ce qui pourrait distraire le cœur du croyant de Dieu: comme la théomnénie (dhikr), le jeûne favorise la concentration des pensées sur le souvenir de Dieu, le recentrement de l'être, la contemplation de Celui qui subsiste «al-Qayyûm».

\section{Conclusion}

Notre étude en trois volets a montré que la pratique du jeûne ne saurait être appréhendée dans son "extériorité ", au moyen d'une observation "clinique » : elle ne peut être déchiffrée que grâce à son inscription au sein d'un cadre théologique donné et en écoutant ce que les personnes de cette tradition ont à en dire, en recueillant le sens qu'elles lui attribuent.

Elle a également montré que dans les trois religions étudiées, le jeûne n'était pas une finalité en soi: il ne s'agit jamais d'une performance à accomplir pour elle-même, mais d'un outil, d'un moyen parmi d'autres, d'un instrument au service de la vie spirituelle. 
L'une de ces finalités est notamment de permettre au sujet adulte de se distinguer de l'animal et de témoigner de son humanité : le jeûne est l'affirmation, par le choix même de l'abstinence, que l'être humain ne se réduit pas aux limites éphémères de son corps. Comme l'écrit T. Goguel d'Allondans,

Le jeûne, privation volontaire de toute nourriture, inscrit le plus souvent dans une croyance, confère au corps la puissance de l'esprit; détachement des réalités les plus absconses, transcendance, mais aussi ascèse [...] épreuve visant à s'assurer ou conforter les capacités à tenir, soutenir une responsabilité, un statut, un rang, il touche aux bords de l'existence humaine. (Goguel d'Allondans 1998, 116)

«Le jeûne confère au corps la puissance de l'esprit »: dans la pratique du jeûne, le corps ne saurait être envisagé comme un réceptacle à emplir. Il n'est point «objet », il devient langage, parole, énonciation à la première personne du singulier, avènement du sujet adulte et raisonnable.

Le «jeûne », entendu comme privation volontaire ponctuelle, travail sur soi, dit le refus d'être esclave, le refus de devenir «objet ", d'être manipulé, instrumentalisé, exploité. Ce sevrage, ce détachement libérateur, cet effort, permet l'avènement du "sujet humain» dans toute sa dignité: il permet la libération de l'Être et la conquête d'une liberté intérieure.

Véritable effort de détachement, le jeûne est un moyen pour l'humain de rester libre à l'égard de ce monde, de contribuer à la libération du sujet humain, de permettre la venue au monde des profondeurs de l'Être. Choisir l'absence de repas, c'est conquérir un espace «à soi ", un espace arraché au monde. Le jeûne, s'il est un "non-acte ", est aussi "un acte» dont le sujet est capable de répondre: c'est un choix pleinement assumé. Le jeûne est recentrement, quête du sens, quête de l'Essence. Le potier, lorsqu'il travaille sur son tour et s'efforce, en modelant le grès humide, de trouver le centre afin de donner à cette terre une forme harmonieuse, doit rester concentré, sur son travail. De même, l'humain qui souhaite donner une forme harmonieuse à cette vie qu'il a reçue doit rester concentré sur le sens de sa vie. Pour les figures ascétiques du judaïsme, du christianisme et de l'islam, il s'agit de jeûner afin de maintenir ses pensées concentrées sur Dieu, de jeûner afin de se souvenir de Dieu: jeûner c'est refuser d'oublier le vrai Dieu. C'est opérer un retour à l'essentiel. Retrouver la juste distance à l'égard du monde. La prescription du jeûne n'a pas pour finalité de détruire le corps, mais de nous permettre de l'habiter de manière harmonieuse. Dans la pratique religieuse du jeûne, le corps devient langage, 
prière. Le choix du jeûne est un choix éminemment humain : en observant un jeûne, "Je" m'affirme intensément comme "sujet».

En outre, notre étude a montré que dans les trois religions étudiées cette pratique était encadrée au moyen de règles d'observances, de modalités, de calendriers délimitant un cadre à l'intérieur duquel le jeûne pourra être observé sans mettre en péril la santé: la pratique religieuse du jeûne se veut respectueuse du corps et de la vie. Elle ne saurait se confondre avec un désir morbide, une fuite du monde, une quête de l'héroïsme ou d'une jouissance masochiste, un refus de la vie. Elle vise à rétablir la juste relation entre le sujet humain et le monde qui l'entoure. Entre l'humain et la Création. Certains versets bibliques et coraniques soulignent la valeur de la Vie, don de Dieu, souffle de Vie, comme le rappelle la Genèse (Gn 1,7) ou encore la sourate de la Prosternation (Qur 32,7-9).

Il appert que cette pratique participe de ce que Benkheira $(1997,29)$ appelle "le dressage des corps ", et qui est selon lui l'une des raisons d'être de la religion. La prescription du jeûne revêt une fonction pédagogique: elle vient structurer notre relation au corps, à la nourriture et au monde. On peut lire dans le livre de la Genèse: "Yhwh Dieu ordre-donne à l'humain [...] de l'arbre de la connaissance du bon et du mauvais, tu n'en mangeras pas (Gn 2,16-17) ». Selon Lydwine Olivier, par cet «ordredonné », Dieu attribue à l'humain la place qui lui revient au sein de la Création (Olivier 2009, 27-28). La limite imposée à l'absolue liberté humaine est aussi ce qui permet la vie. Sans ordre, règne le chaos. Dans le texte coranique, l'interdit est formulé comme suit: «n'approchez pas, tous deux, de l'arbre que voici» (Qur 2,35). L'interdit porte davantage sur un lieu que sur une manducation. L'ordre divin instaure un "Cosmos ", un univers à l'intérieur duquel le sacré s'est manifesté, mettant ainsi fin au «Chaos» (Eliade 2010, 29).

Enfin, observons que la prescription religieuse du jeûne, qui est liée à un calendrier religieux, de même qu'elle instaure un «Temps sacré» (Eliade 2010, 61), participe de la sacralisation ou de la sanctification du corps, et des fruits de la Création. L'ordre divin en assignant une limite à la liberté humaine, permet à l'humain, au sortir de l'Éden, d'apprendre à vivre en société, d'apprendre à contrôler ses désirs et à respecter certains interdits. C'est là aussi l'une des fonctions de la religion: instaurer certaines lois ou règles grâce au respect desquelles le vivre ensemble devient possible. C'est

8. Traduction Olivier $(2009,27)$. 
pourquoi la prescription religieuse condamne ou rend licite. Telle est d'ailleurs la fonction du rituel, selon Jambet:

Il n'y a pas de religion sans rituel, et sans ritualité. Or, la ritualité des actions n'est pas une propriété intellectuelle ou morale, mais la sacralisation des actes licites, recommandés ou obligatoires, la condamnation des actes interdits, au point aveugle de l'union de l'âme et du corps. (Jambet 2011, 101)

Cette prescription religieuse, en explicitant les modalités du jeûne et de sa rupture, rend également licite l'acte de se nourrir. L'observance d'une telle privation permet donc symétriquement la célébration des fruits de la Création au cours d'un repas: elle permet d'apprécier, sans mauvaise conscience, la saveur d'un «dé-jeûner ». Loin de signifier un rejet du corps, ou du monde, cette pratique permet à l'humain de prendre la place qui lui revient dans la Création, de structurer sa relation au corps et au monde, de vivre non dans un Chaos, mais dans un Cosmos.

Ainsi, jeûne et "dé-jeûner » fonctionnent comme un couple dont les deux termes, sur le plan symbolique, se renforcent mutuellement: plus le jeûne qui précède ou suit un repas est long, plus la valeur symbolique du repas en question sera chargée. Dans l'histoire du christianisme, la communion puise sa charge symbolique dans le jeûne eucharistique observé depuis la veille; la charge symbolique de l'agneau du dimanche de Pâques est accrue du fait de la privation de nourriture carnée durant le Carême; durant le Ramaḍân, l'ifțâr revêt un caractère solennel en raison du jeûne diurne qui le précède: une période de privation renforce la charge symbolique du repas qui y met un terme. Pareillement, durant ce même mois, le repas pris avant l'aube (sahûr) revêt un caractère religieux en raison du jeûne qui suivra; le repas qui précède le jour de Kippour revêt un caractère méritoire et obligatoire en raison du jeûne à venir. Le jeûne renforce la valeur symbolique du repas qui le précède ou qui lui succède: dans le couple que forment le jeûne et le repas, la rigueur du premier renforce la charge symbolique du second. Ce qui confère sa force symbolique au Dernier Repas, ce n'est pas nécessairement le repas en lui-même, mais la privation qu'il annonce, et le caractère définitif et absolu de cette dernière. C'est de ce jeûne absolu, illimité et héroïque qui lui succède, que le «Dernier repas» tire toute sa force symbolique. 


\section{Références}

AL-GHAzÂlî,, (m. 1111) (2001), Les Secrets du jeûne en islam. La vivification des sciences de la religion / intro., notes et trad. par M. Gloton, Beyrouth, Dâr Al-Bouraq.

Annestay, J. (2009), Une femme soufie en islâm. Rabi'a al-'Adawiyya, Paris, Entrelacs.

Assouly, O. (2002), Les nourritures divines, Essai sur les interdits alimentaires, Arles, Actes Sud.

Bauer, J. (2011), «Yom Hashoah. Jour commémoratif de l'Holocauste, dans le calendrier juif canadien ", Studies in Religion / Sciences Religieuses, 40/3, p. 337-350.

Baumgarten, J. (2001), Récits hagiographiques juifs, Paris, Cerf.

Benkheira, M. H. (2000), Islâm et interdits alimentaires, Paris, Presses Universitaires de France.

Benkheira, M. H. (1997), L'Amour de la loi. Essai sur la normativité en islâm, Paris, Presses Universitaires de France.

Brague, R. (2009²) [2008], Du Dieu des chrétiens et d'un ou deux autres, Paris, Flammarion.

BukнÂrî, Al- (m. 256h.) (2003 - 1424 h), Le Șahîh d'al-Bukhârî. Les hadith authentiques par le grand traditionniste l'Imam Abu 'Abdallah Muhammad b. 'Ismail Al-Bukhârî / trad. par A. Harkat, Al-Maktaba al- 'Asriyyah, Beyrouth, Saïda.

Bynum, C. (1994) [ang. 1987], Jê̂nes et festins sacrés, Paris, Cerf.

Del Vasto, L. (1945), Principes et préceptes du retour à l'évidence, Paris, Denoël.

Devret, C. (1967), Massignon et Gandhi: La contagion de la vérité / préf. de Y. Moubarac, Paris, Seuil.

Dousse, M. (2002), Dieu en guerre. La violence au cour des trois monothéismes, Paris, Albin Michel.

Duhaime, J. (1998), «Lois alimentaires et pureté corporelle dans le Lévitique. L'approche de Mary Douglas et sa réception par Jacob Milgrom », dans J. Duhaime, dir., Nourriture et sacré, Religiologiques, 17, p. 19-35.

Eliade, M. (2010), Le sacré et le profane, Paris, Gallimard.

Fenton, P. B. (1987), Deux traités de mystique juive. 'Obadyah b. Abraham b. Moïse Maïmonide, "Le traité du puits». David b. Josué, dernier des Maïmonide, "Le Guide du détachement » / préf. de G. Vajda, Lagrasse, Verdier. 
Feuillebois-Pierunek, E. (2006), "La maîtrise du corps d'après les manuels de soufisme (X $\mathrm{X}^{\mathrm{e}}-\mathrm{XIV}^{\mathrm{e}}$ siècles) ", dans Le corps et le sacré en Orient musulman, Revue des mondes musulmans et de la Méditerranée, 113-114, p. 91-107.

Geoffroy, E. (2003), Initiation au soufisme, Paris, Fayard.

Gimaret, D. (I988), Les noms divins en islam, exégèse lexicographique et théologique, Paris, Cerf.

Gobillot, G. (1996), Al-Hakîm al-Tirmidhî. Le livre de la profondeur des choses, Paris, Presses Universitaires du Septentrion.

Goguel D'Allondans, T. (1998), «Se nourrir et grandir. De l'importance de quelques comportements alimentaires lors des rites de passage ", dans J. Duhaime, dir., Nourriture et sacré, Religiologiques, 17, p. 113-122.

Goitein, S. D. (2006) [1966], «Ramadan, the Muslim Month of Fasting», dans The Formation of the classical Islamic world, 26, p. 151-171.

Gramlich, R. (1997), Weltverzicht, Grundlagen und Weisen islamicher Askese, Wiesbaden, Harrowitz V.

Greenstone, J. H. (1945), Jewish Feasts and Fasts, Philadelphia, Press of the Jewish publication Society.

Gugenheim, E. (1978) [1961], Le judaïsme dans la vie quotidienne, Paris, Albin Michel (Présence du judaïsme).

Haddad, P. (2006), «Le sens des jeûnes », conférence vidéo et documents, disponible sur: <http://www.akadem.org/sommaire/themes/vie-juive/ les-fetes/jours-de-jeunes/le-sens-des-jeunes-08-05-2006-6649_360.php>.

Haft, C. (1973), «L'institution totalitaire. Le moral et la morale dans les camps de concentration nazis ", L'Homme et la société, 29-30, p. 45-57.

Harrus-Révidi, G. (1994), Psychanalyse de la gourmandise, Paris, Payot \& Rivages (Petite Bibliothèque Payot).

Heyberger, B. (2006), "Les transformations du jeûne chez les chrétiens d'orient", dans Le corps et le sacré en Orient musulman, Revue des mondes musulmans et de la Méditerranée, 113-114, p. 267-285.

IbN 'Arabî (m.1240) (1996²), Textes sur le jê̂ne / trad. et intro. par A.-R. YAHYÂ (C.-A. GILIS), Beyrouth, Dâr Al-Bouraq.

IDEL, M. (1991), Maïmonide et la mystique juive, Paris, Cerf.

Jамвет, C. (2011), Qu'est-ce que la philosophie islamique?, Paris, Gallimard.

Junayd, -Al (m. 911) (1983), Enseignement spirituel, Paris, Actes Sud. 
Kanafani-Zahar, A. (2006), «Le Carême et le Ramadan. Recréer le corps. Un cas libanais» dans Le corps et le sacré en Orient musulman, Revue des mondes musulmans et de la Méditerranée, 113-114, p. 287-300.

Khalidi, T. (2003), Un musulman nommé Jésus. Dits et récits dans la littérature islamique, Paris, Albin Michel (L'islam des Lumières).

Khoury, E. (1966), "Les canons sur l'eucharistie dans Kitâb al-hudâ», Parole de l'Orient: revue semestrielle des études syriaques et arabes chrétiennes, 2/2, p. 251-271.

Lipsyc, S. S. (2011), "Solidarité avec les femmes en attente de leur divorce religieux (guet) ", Judaïsmes et questions de société, non paginé, disponible sur: <http://judaismes.canalblog.com/archives/2012/03/06/23694345.html>.

LuTHER, M. (1999). "À la noblesse chrétienne de la nation allemande sur l'Amendement de l'État chrétien ", Euvres, vol. 1, Paris, Gallimard, p. 589-673.

Luzzatto, M. H. (1956), Le sentier de rectitude, Paris, Presses universitaires de France (Collection Sinai).

MaÏmonide, M. (m.1204) (2003), Le Guide des égarés / trad. par S. Munk, Paris, Maisonneuve \& Larose.

Massignon, L. (1922), Passion d'al-Hosayn-Ibn-Mansour al-Hallaj, Paris, P. Geuthner.

(1997), Les trois prières d'Abraham, Paris, Cerf.

(2011) Badaliya: Au nom de l'autre (1947-1962) / édité par M. Borrmans. et F. Jacquin, préf. de J.-L. Tauran, Paris, Cerf.

Melchert, C. (1996), "The Transition from Asceticism to Mysticism at the Middle of the Ninth Century C. E. », Studia Islamica, 83, p. 51-70.

Meslin, M. (I988), L'expérience humaine du divin. Fondements d'une anthropologie religieuse, Paris, Cerf.

Müller, J.-M. (2010), Désarmer les dieux. Le christianisme et l'islam an regard de l'exigence de non-violence, Gordes, Les Editions du Relié.

Noce, C. (2011), "Il digiuno nel christianesimo antico», dans I. De Francesco, C. Noce et M. B. Artioli, dir., Il digiuno nella chiesa antica. Testi siriaci, latini e greci, Milano, Paoline, p. 49-174.

Noyé, J.-C. (2007), Le grand livre du jeûne, Paris, Albin Michel.

Olivier, L. (2009), "Analyse processuelle de Genèse 2,4b-25. Incidences herméneutiques et théologiques », Université de Montréal, Faculté de théologie et de sciences des religions. 
Ollivry, F. (2006), Les Secrets d'Alep, une grande ville arabe révélée par sa cuisine, Arles, Actes Sud (Sindbad).

Pénicaud, M. (2010), "Le Réveil des Sept Dormants. Anthropologie d'un pèlerinage islamo-chrétien en Bretagne », Université de Provence, Faculté des lettres et sciences humaines.

Perrot, C. (1993²), Jésus et l'histoire, Paris, Desclée/Mame.

Ruben-Hayoun, M. (2001), "Le corps dans la tradition juive ", dans G. Comeau, dir., Le corps. Ce qu'en disent les religions, Paris, Ed. de l'Atelier, p. 31-54.

RûMî, J. (m.1273) (1982), Le livre du dedans (fîhi-mâ-fîhi) / trad. par E. de Vitray-Meyerovitch, Paris, Actes Sud.

Schimmel, A. (1996) [ang. 1975], Le soufisme ou les dimensions mystiques de l'islam, Paris, Cerf.

Shenouda III, H. H. Pope (1990), The spirituality of Fasting, Cairo, Coptic Orthodox Patriarchate.

Siméant, J. (2009), La grève de la faim, Paris, Presses de Sciences Politique.

Sinn, S., C. Bock et R. Deffenbaugh (2013), «Jeûner pour la justice climatique. Une perspective luthérienne ", The Lutheran World Federation, p.1-5, disponible sur: <https://www.lutheranworld.org/sites/default/ files/Jeune_pour_la_justice_climatique.pdf >.

Soufi, D. (2012). «Fasting», Encyclopæedia Iranica, non paginé, disponible sur: $\langle$ http://www.iranicaonline.org/articles/fasting >.

SÜsskind-Goldberg, M. (2007), "Des solutions au problème des femmes agounot ", Pardès, 43/2, p. 207-216.

Tertullien (1852), Euvres de Tertullien / trad. par E-A De Genoude, Paris, Louis Vivès.

Vajda, G. (1938), "Jeûne musulman et jeûne juif », Hebrew Union College Annual, 12-13, p. 367-385. (1947), Introduction à la pensée juive du Moyen-Âge, Paris, Vrin. (1964), «Le rôle et la signification de l'ascétisme dans la religion juive ", Archives de sociologie des religions, 18/1, p. 35-43.

Vuillaume, C. (1989), «Le Jeûne dans la tradition monastique ancienne et aujourd'hui (I) », Collectanea Cisterciensia, 51, p. 42-78. 


\section{Ouvrages de référence et leurs abréviations}

La Bible, Notes intégrales, Traduction œcuménique (2011), Paris, Cerf/ Bibli'o (Les titres des livres bibliques sont abrégés selon l'usage).

$\mathrm{DB}=$ Dictionnaire de la Bible (1910), F. Vigouroux, dir., Paris, Letouzey et Ané.

DC = Dictionnaire du Coran, (2007) M. A. Amir Moezzi, dir., Paris, Robert Laffont (Bouquins).

DEJ = Dictionnaire Encyclopédique du judaïsme (1993), G. WIGODER, dir., Paris, Cerf.

DM = Dictionnaire des monothéismes (2013), C. Michon et D. Moreau, dir., Paris, Seuil.

EIS = Encyclopédie de l'Islam (1998), Leiden, Brill.

ML = Mu'jam maqâyis al-lugha (1979), A. IBN FÂRIs et 'A. al-S. HÂrûN, dir., Dâr al-Fikr, Beyrouth.

$\mathrm{TJ}=$ Le Talmud de Jérusalem (1886) / trad. par M. Schwab, Paris, Maisonneuve et Ch. Leclerc.

Qur = al-Qur'ân: Le Coran (1959) / trad. par M. Hamidullah,; (1967) / trad. par D. Masson, Paris, Gallimard; (2002) / trad. par J. Berque, Paris, Albin Michel.

\section{Résumé}

Tandis que le repas occupe une place importante dans la vie religieuse juive, chrétienne ou musulmane, il appert que la pratique du jeûne y occupe elle aussi une place centrale. Qu'implique cette prescription au plan théologique ? Comprend-elle une exhortation à renoncer à nourrir l'organisme, à mépriser ce monde? Ou bien a-t-elle au contraire pour fonction de nous préparer à célébrer les fruits de la Création au cours d'un repas? De nous permettre de mieux apprécier la saveur d'un «dé-jeûner »? J'explore dans cet article les implications théologiques du jeûne dans le judaïsme, le christianisme et l'islam. J'étudie les écrits de certaines figures spirituelles (mystiques, moines, ascètes) relatifs à cette pratique et je m'efforce de comprendre quelle relation au corps, à la Création, à la vie et à la mort induit le jeûne dans les trois religions étudiées. 


\section{Abstract}

Whereas the meal occupies an important place in Jewish, Christian or Muslim religious life, it appears that fasting also occupies a central place in these traditions. What does this religious obligation imply theologically? Is fasting an exhortation to forego feeding the body, to scorn this world? Or, on the contrary, is fasting a practice preparing us to celebrate the fruits of Creation during a meal? To better appreciate the taste of a "break-fast»? In this article, I will explore the theological implications of fasting in Judaism, Christianity and Islam. I will study the writings of some spiritual figures (mystics, monks, ascetics) related to this practice and try to understand what relationship fasting induces with the body, Creation, life and death in each of these three religions. 